\title{
Presentation and Publication Rates among Women and Men at AAO-HNS Meetings
}

\author{
Marc A. Cohen ${ }^{a}$ Natasha Mirza ${ }^{b}$ Kristel Dow $^{b}$ Soo Kim Abboud ${ }^{b}$ \\ ${ }^{a}$ Department of Otolaryngology, Head and Neck Surgery, Weill Cornell Medical College, New York, N.Y., and \\ ${ }^{b}$ Department of Otolaryngology, Head and Neck Surgery, University of Pennsylvania School of Medicine, \\ Philadelphia, Pa., USA
}

\section{Key Words}

Women in otolaryngology $\cdot$ Publication rates $\cdot$ Abstract submission - Time to publication

\begin{abstract}
Objective: We attempted to assess the percentages of abstracts submitted to annual American Academy of Otolaryngology, Head and Neck Surgery (AAO-HNS) meetings from 2000 to 2004 by both women and men. We sought to determine the subsequent peer-reviewed overall publication rates for all submissions. We also studied trends of submission among female presenters and compared them to males. Study Design: Cross-sectional study. Setting: Tertiary academic medical center. Methods: 2,463 total abstracts presented between 2000 and 2004 were searched in the computerized databases Medline and Pubmed in 2008. The published articles were examined by reviewers to assess publication rate, time to publication, gender of authorship and subspecialty of publication. Results: 1,413 (57.35\%) posters and 1,051 (42.65\%) oral presentations were presented from 2000 to 2004 . Of the 1,413 posters presented, 275 (19.46\%) were presented by female first authors. The female first-author poster publication rate was $33.81 \%$, while the male first-author poster publication rate was $36.99 \%$ ( $p=$
\end{abstract}

0.353). Of 1,051 oral presentations, 154 (14.65\%) were presented by female first authors. The male first-author oral presentation publication rate was $60.98 \%$, while the female firstauthor oral presentation publication rate was 59.09\% ( $p=$ $0.657)$. There were no statistical differences in time to publication for posters $(p=0.796)$ or oral presentations $(p=0.737)$ between the genders. The majority of female first-author submissions involved pediatric (29.94\%) and general (17.88\%) otolaryngology. Conclusion: While women are increasingly drawn to otolaryngology, they represented less than $20 \%$ of total submissions at the annual AAO-HNS meetings from 2000 to 2004. Women more commonly submit poster than oral presentations. The eventual publication rates of abstracts and the average time to publication of presentations are equal between the genders.

Copyright $\odot 2013$ S. Karger AG, Basel

\section{Introduction}

In the field of otolaryngology, there are multiple national and international meetings attended yearly, with the largest being the American Academy of Otolaryngology, Head and Neck Surgery (AAO-HNS). The oral and written presentations presented at the Academy reach

\section{KARGER}

Fax +4161306 1234

E-Mail karger@karger.ch

www.karger.com
(C) 2013 S. Karger AG, Basel

$0301-1569 / 12 / 0746-0325 \$ 38.00 / 0$

Accessible online at:

www.karger.com/orl
Marc A. Cohen, MD

Department of Otolaryngology, Head and Neck Surgery, Weill Cornell Medical College 1305 York Avenue, 5th Floor

New York, NY 10021 (USA)

E-Mail mac2093@med.cornell.edu 
more than 6,000 health care professionals per year. The quality of research presented at conferences is ultimately decided by eventual publication in peer-reviewed journals. There is currently no study determining what percentage of presentations survive a peer-reviewed process in otolaryngology. Eventual publication rates have been assessed in specialties such as anesthesiology, pediatrics and general surgery, and are about 50\% [1-3].

In the past 20 years, the number of women in otolaryngology has increased dramatically. As noted by Ferguson and Grandis, the number of female otolaryngology residents has increased from $5 \%$ in 1980 to $22.8 \%$ in 2004, while the number of practicing female otolaryngologists has increased even more dramatically in a shorter period of time (from 6\% in 1998 to $24 \%$ in 2005) [4]. As noted in the same study, only 2 of 90 (2.2\%) academic departments were headed by women in 2006. Furthermore, the relative contributions of presentations and publications at the AAO-HNS meeting have yet to be determined. In other words, no study has yet researched what percentages of presentations include female first and last authors (the individuals who perform the most work and guidance on a project, respectively). In addition, there is minimal data regarding the specific subspecialty pursuits among women in otolaryngology.

The aim of this study was to assess the number of abstracts presented at the annual AAO-HNS meetings over a 5-year period (2000-2004) by both women and men. The study also sought to determine the subsequent peerreviewed publication rate for all studies as well as to determine if there was a significant difference between both the presentation and publication rates. Additionally, trends among female presenters were studied, including whether female presenters were more likely to be accepted for oral or poster presentations, and to identify specific subspecialties within otolaryngology in which women were more likely to submit presentations.

\section{Materials and Methods}

Two thousand four hundred and sixty-three total abstracts presented between 2000 and 2004 at the annual AAO-HNS meetings were searched in the computerized database Pubmed (Medline) in the summer of 2008 by two reviewers. Searches were conducted with initial search by first author and a key word from the title or abstract. If not successful, this was followed by a search of the subsequent authors. All authors' names were searched before declaring an abstract unpublished. To determine interobserver reliability, abstracts were searched by two reviewers and the findings were compared.
The published articles were examined to assess poster and oral publication rate, time to publication, and the gender of the first and last authors. Publication journals were noted, as were any changes in the number of authors or lead author. Subject/subspecialty information was also documented for each abstract and publication. In order to standardize the searching process, only published papers that were nearly identical (corresponding hypotheses, study designs or protocols, or studies with similar number of specimens and/or similar results) to presented papers were included as a match. In addition, papers that contained all of the data presented within the abstract, but also included additional data, were regarded as a match. However, those papers that did not match nearly identically, despite similar techniques or study design, were not included. When we identified differences in the title or authors of a final publication, we compared the content of the original abstract with that of the final publication provided to determine eligibility. This stringent criterion has been used in prior studies [1,5-12]. No effort was made to check for multiple papers stemming from a single abstract; once a suitable match was found, the search was concluded. All data were entered into a database with the journal name and time of publication. Time to publication was rounded to the nearest month. Articles published in journals where only the year was available were given the date of January of the year they were published. Articles published in peer-reviewed journals before being presented at appropriate AAO-HNS annual meetings were given negative numbers. Abstracts were classified according to subspecialty; these included general otolaryngology, pediatric otolaryngology, otology, rhinology, facial plastic surgery, laryngology, head and neck, and basic science.

Statistical analyses were performed with the Statistical Package for the Social Sciences (SPSS version 15.0, Chicago, Ill., USA). Nonparametric statistics were computed using two-sided Fisher's exact test and Pearson's $\chi^{2}$ tests. $t$ tests were used to detect statistical differences in time to publication comparisons between men and women. Results were considered statistically significant when $\mathrm{p}$ values were less than 0.05 .

\section{Results}

There were 1,413 (57.35\%) poster and 1,051 (42.65\%) oral presentations presented between 2000 and 2004. Of the 1,413 posters presented, 275 (19.46\%) were presented by female first authors. The overall publication rate in peer-reviewed journals was 514 of 1,413 posters, or $36.37 \%$, of posters. Of the 514 published, 93 (18.09\%) of those had female first authors (table 1). Eighty-three of the $514(16.15 \%)$ published had female last authors. Twenty-six of the 514 (5.06\%) posters presented that were eventually published had both female first and last authors. The male first author poster publication rate was 36.99\%, while the female first author poster publication rate was $33.81 \%(\mathrm{p}=0.353)$. There was no statistical difference in time to publication among poster presentations that were authored first by men or women ( $\mathrm{p}=0.796$; table 2$)$. 
Table 1. Total number of poster and oral presentations with respect to gender and publication rates (with percent of publications in parentheses)

\begin{tabular}{lcrr}
\hline & Poster total & Oral total & Abstract total \\
\hline Female first author & $275(33.8)$ & $154(59.1)$ & $429(42.9)$ \\
Male first author & $1,138(37.0)$ & $897(61.0)$ & $2,035(47.6)$ \\
All authors & $1,413(36.4)$ & $1,051(60.7)$ & $2,464(46.8)$ \\
Female first author, \% & 19.5 & 14.7 & 17.4 \\
\hline
\end{tabular}

Table 2. Time to publication following presentation at AAO-HNS meetings with respect to gender and presentation type

\begin{tabular}{lllrl}
\hline & $\begin{array}{l}\text { Female } \\
\text { first author }\end{array}$ & $\begin{array}{l}\text { Male } \\
\text { first author }\end{array}$ & All authors \\
& 19.38 & 18.95 & 19.10 & 0.796 \\
Time to publication following poster, months & 15.00 & 15.59 & 15.50 & 0.737 \\
Time to publication following oral presentation, months & & & \\
\hline
\end{tabular}

$\mathrm{p}$ values assessed by the t test.

Of 1,051 oral presentations, 154 (14.65\%) were presented by female first authors. The overall publication rate for all oral presentations was 638 of 1,051 , or $60.70 \%$. Of the 638 published, 91 had female first authors (14.26\%) and 88 (13.79\%) had female last authors (table 1). Twenty-four of the 638 oral presentations that were published had both female first and final authors (3.76\%). The female first author publication rate was $59.09 \%$, while the male first author oral presentation publication rate was $60.98 \%(\mathrm{p}=$ 0.657 ). There was no statistical difference in time to publication among oral presentations that were first authored by men or women $(\mathrm{p}=0.737$; table 2$)$.

Women presented poster presentations more frequently than oral presentations, whether they were first or last authors $(\mathrm{p}=0.002$ for first authors, $\mathrm{p}=0.023$ for last authors). The largest percentage of female first author presentations involved pediatric $(29.94 \%)$ and facial plastics (19.12\%) topics; female last author presentations were found most commonly in the areas of pediatric otolaryngology (19.88\%), followed by otology in $17.68 \%$ of submissions.

\section{Conclusion}

To determine the quality of research at major conferences, it is useful to understand the publication rate of abstracts presented. If the publication rate falls below the average publication rate of other meetings, this may reflect poorly on the quality of both the presentations and the meeting. A critical examination of the data provides feedback to the program selection committee regarding the stringency of their selection criteria. Publication in a peer-reviewed journal offers a lasting record of a study's scientific contribution and is the ultimate goal of those presenting at national meetings.

Failure to publish has been attributed to lack of time to submit papers to peer-reviewed journals as well as rejection by peer-reviewed journals. This study made no attempt to contact the authors of abstracts who failed to publish. However, other studies have looked into this. Riordan [13] surveyed 88 of 89 authors whose abstracts, presented at two international pediatric meetings, were not followed by a publication. This publication supports the findings of others, identifying the major reason for nonpublication as a simple failure of the investigators to submit papers to peer-reviewed journals [13-15]. Weber et al. [14] conducted a review to identify all abstracts presented at a medical meeting in 1991 that were not followed by publication of a paper within 5 years. This study found that only 44 (20\%) of the 223 respondents had submitted their manuscripts to journals. Manuscript submission was not associated with abstract quality, positive results, or other study characteristics.

Our study did not identify which authors were medical students, residents, fellows, researchers or attending level otolaryngologists. The transient nature of all of these jobs, in conjunction with a disparate level of interest and insufficient time, often renders publication challenging [9].

To our knowledge, this is the only study to determine publication rates among otolaryngology abstracts pre- 
sented at the annual AAO-HNS meeting over a recent and extended period. It is also the only study to compare gender-specific publication rates, time to publication, and subject/subspecialty information in otolaryngology. Peng et al. [16] reviewed abstracts presented at the AAOHNS annual meeting in 1999, and determined that the median publication time was 16 months, with a publication rate of $50 \%$. While they reviewed abstracts from only 1 year, they did identify significant predictive factors of publication success. Roy et al. [15] reviewed abstracts presented at the Otorhinolaryngological Research Society meetings from 1978 to 1995 and reported a publication rate of $69.09 \%$ with an average time to publication of 22.5 months; however, they did not seek to determine if gender played a role in publication success or time to publication. Bhattacharyya and Shapiro [17] published a paper noting that the average number of publications declined significantly for young academic otolaryngologists between the 1980s and the 1990s; again, the study did not look at potential gender-specific differences. In summary, our study is the only study to review publication rates and time to publication of abstracts presented at the annual AAO-HNS meeting over a recent 5 -year period; in addition, it is the only study to determine if gender-specific differences exist in these and other parameters.

Overall, $46.8 \%$ of all presentations (poster and paper) at the annual AAO-HNS meetings in the years 20002004 were published. This compares with publication rates for other medical specialties: orthopedics $64 \%$, anesthesia $50 \%$, ophthalmology $60 \%$, surgery $57 \%$ and pediatrics $48 \%[1-3,8,18]$.

Women accounted for $14.65 \%$ of first authors delivering oral presentations and $19.46 \%$ of first authors giving poster presentations. On quick review, these numbers appear to be lower than the number of females in otolaryngology residencies noted by Ferguson and Grandis (22.8\% in 2004) [4]. However, there may in fact be minimal or no discrepancy between females in otolaryngology and submission percentages. We assessed abstracts from 2000 to 2004 (implicating the work was likely performed in the prior year or so) and the percentage of females in practice in 1998 may be as low as 6\% [4]. A more current evaluation of the relative contributions of the genders is a topic that requires further investigation as one study in 2004 based on survey data from 1998 noted that when adjusted for academic rank, male academicians had more peer-reviewed publications than their female counterparts [19].

As the number of females within otolaryngology continues to increase, we anticipate academic productivity among women to rise. The eventual publication rates of abstracts presented by female authors as well as the average time to publication appear equal to that of men. Women more commonly submit poster presentations rather than paper presentations - a difference that was noted to be statistically significant, although the reasons for this are yet unknown. A potential explanation for this discrepancy might be that women prefer poster presentations because they do not have to present in person. If this is the case, the number of female otolaryngologists presenting oral presentations may rise as we enter the age of webinars and teleconferencing. Furthermore, pediatric otolaryngology was most commonly represented among both poster and oral presentations, and this result was statistically significant for both female first $(p=0.002)$ and last authors $(p=0.023)$. Grandis et al. [19] noted that women were more likely to select pediatric otolaryngology fellowship training, whereas men most often selected fellowships in facial plastic surgery.

This study had several limitations. Articles published in journals not accessed by Pubmed (Medline) were not identified in the search. Our search results would have failed to identify peer-reviewed publications in journals not indexed in these databases. Abstracts may have undergone such major changes to both study design and authorship that they may be unrecognizable in a Pubmed search. It was assumed that all peer-reviewed publications result from a single abstract; however, a single publication may arise from multiple abstracts or data from a single abstract may lead to multiple publications, which can affect publication rates. It is also possible that some abstracts are yet to be published. However, research has shown that $90 \%$ or more of studies are published within 4 years of the meeting $[12,13,15]$. While some may also question the validity of peer review as the gold standard of research quality, scientific peer review remains the standard by which the quality of science is assessed [20]. There is also the danger that the abstract peer review process is actually leading to the underreporting of valid research. A study of abstracts not published at a scientific meeting found that researchers whose abstracts were rejected by a scientific meeting were significantly more likely to believe that a journal would reject their full manuscript [14].

Further study is required to assess for disparity and address any causes that lead to differences in presentation and publication rates in women compared to men. As more women enter the otolaryngology workforce, it is imperative to look at factors that influence subspecialty choices as well as academic productivity. Furthermore, prospective assessment is useful in determining the root causes of gender differences in otolaryngology. 


\section{References}

$>1$ McCormick MC, Holmes JH: Publication of research presented at the pediatric meetings. Change in selection. Am J Dis Child 1985; 139:122-126.

$>2$ Yentis SM, Campbell FA, Lerman J: Publication of abstracts presented at anaesthesia meetings. Can J Anaesth 1993;40:632-634.

3 Easterbrook PJ, Berlin JA, Gopalan R, Matthews DR: Publication bias in clinical research. Lancet 1991;337:867-872.

$>4$ Ferguson BJ, Grandis J: Women in otolaryngology: closing the gender gap. Curr Opin Otolaryngol Head Neck Surg 2006;14:159_ 163.

$\checkmark 5$ Goldman L, Loscalzo A: Fate of cardiology research originally published in abstract form. N Engl J Med 1980;303:255-259.

6 Gorman RL, Oderda GM: Publication of presented abstracts at annual scientific meetings: a measure of quality? Vet Hum Toxicol 1990;32:470-472.

$\checkmark 7$ Hamlet WP, Fletcher A, Meals RA: Publication patterns of papers presented at the Annual Meeting of the American Academy of Orthopaedic Surgeons. J Bone Joint Surg Am 1997;79:1138-1143.
8 Juzych MS, Shin DH, Coffey J, Juzych L, Shin D: Whatever happened to abstracts from different sections of the association for research in vision and ophthalmology? Invest Ophthalmol Vis Sci 1993;34:1879-1882.

$\checkmark 9$ Juzych MS, Shin DH, Coffey JB, Parrow KA, Tsai CS, Briggs KS: Pattern of publication of ophthalmic abstracts in peer-reviewed journals. Ophthalmology 1991;98:553-556.

10 Landry VL: The publication outcome for the papers presented at the 1990 ABA conference. J Burn Care Rehabil 1996;17:23A-26A.

11 Meranze J, Ellison N, Greenhow DE: Publications resulting from anesthesia meeting abstracts. Anesth Analg 1982;61:445-448.

12 Scherer RW, Dickersin K, Langenberg P: Full publication of results initially presented in abstracts. A meta-analysis. JAMA 1994;272: 158-162.

13 Riordan FA: Do presenters to paediatric meetings get their work published? Arch Dis Child 2000;83:524-526.

14 Weber EJ, Callaham ML, Wears RL, Barton C, Young G: Unpublished research from a medical specialty meeting: why investigators fail to publish. JAMA 1998;280:257-259.
15 Roy D, Sankar V, Hughes JP, Jones A, Fenton JE: Publication rates of scientific papers presented at the Otorhinolaryngological Research Society meetings. Clin Otolaryngol Allied Sci 2001;26:253-256.

16 Peng PH, Wasserman JM, Rosenfeld RM: Factors influencing publication of abstracts presented at the AAO-HNS annual meeting. Otolaryngol Head Neck Surg 2006;135:197-203.

17 Bhattacharyya N, Shapiro NL: Academic otolaryngology in the new millennium: we are falling behind. Otolaryngol Head Neck Surg 2007; 137:535-538.

18 Nguyen V, Tornetta P 3rd, Bkaric M: Publication rates for the scientific sessions of the OTA. Orthopaedic Trauma Association. J Orthop Trauma 1998;12:457-459, discussion 456.

19 Grandis JR, Gooding WE, Zamboni BA, et al: The gender gap in a surgical subspecialty analysis of career and lifestyle factors. Arch Otolaryngol Head Neck Surg 2004;130:695702 .

20 Relman AS: Peer review in scientific journals - what good is it? West J Med 1990;153: 520-522. 